\title{
The Validity of the Purchasing Power Parity Hypothesis for Kuwait
}

\author{
Ebrahim Merza ${ }^{1}$ \\ ${ }^{1}$ Economic Department, Kuwait University, Kuwait \\ Correspondence: Ebrahim Merza, Economic Department, Kuwait University, Kuwait. E-mail: \\ emerza@gmail.com
}

Received: August 12, 2016

Accepted: September 6, 2016

Online Published: November 4, 2016

doi:10.5539/mas.v11n1p188

URL: http://dx.doi.org/10.5539/mas.v11n1p188

\begin{abstract}
Many studies have tested the null hypothesis of the unit root of the real exchange rate to examine the validity of the purchasing power parity (PPP) hypothesis. Previous studies have reached different conclusions regarding that issue. This study tests the hypothesis of PPP in Kuwait using two tests of unit roots, the Augmented Dickey Fuller (ADF) and Phillips Perron (PP) tests. Using monthly data from 2006 to 2015, both tests reject the PPP hypothesis for the Kuwaiti economy. Using the components of the real exchange rate, we find that the levels of prices in both Kuwait and the US are not moving together to provide stationarity for the real exchange rate. This result could be attributed to the large increases in the prices of the housing and food and beverages sectors in Kuwait during that time.
\end{abstract}

Keywords: PPP hypothesis, adf test, PP test, real exchange rate, Kuwait

\section{Introduction}

The Purchasing Power Parity (PPP) hypothesis is considered an old hypothesis in the field of international economics. It was first introduced by the Swedish economist, Gustan Cassel in 1918. He proposed this method as a base for determining the official exchange rates of countries at the end of World War I. Afterward, the PPP hypothesis became widely used by central banks and policy makers as an indicator to assess the value of a currency when it deviates from its equilibrium value(Shapiro, 2006).

The PPP hypothesis states that the cost of similar goods and services in different countries tends to be equal in the long run. This conclusion assumes that the exchange rate adapts to eliminate the potential for any profits from buying a product in one country and selling it in another country.

The PPP hypothesis could be considered extension of the "law of one price". This law stipulates that similar goods should be sold in integrated markets at similar prices, assuming the absence of transportation costs or any type of barriers to trade. If there are different prices, then there will be opportunities to make profits by buying the commodity from the market with low prices and selling it in markets with high prices. If this process continues, prices will tend to be equal in the end due to supply and demand forces.

The verification of the PPP hypothesis is questionable due to the difficulties of integrating markets and the elimination of barriers to trade. The question about the credibility of the PPP hypothesis was raised after the collapse of the Bretton Woods system in 1973 and the transition to a floating exchange rate.

A number of studies have shown problems with adopting the PPP hypothesis in the short term; however, in the long run, there is no conclusive result of its failure (Nusair, 2003).Even though opinions about the validity of the PPP hypothesis vary, Holmes (2001) argues that PPP method is a convenient method to estimate the exchange rate and to determine whether the currency has appreciated or depreciated.

This research focuses on testing the validity of the PPP hypothesis for the Kuwaiti economy using monthly data from 2006 to 2015. This paper continues in the following order. Part 2 presents the theoretical framework and the previous literature. Part 3 gives an overview of the methodology. Part 4 analyzes the empirical results. Finally, Part 5 provides the conclusions of the study.

\section{The Theoretical Framework and Previous Studies}

The general formula for the hypothesis of purchasing power parity (PPP) states that the cost of identical goods and services in different countries tends to be equal in the long run. This hypothesis can be expressed in the absolute form and the relative form. The absolute form of the PPP hypothesis says that the exchange rate will 
lead the relative prices between the two countries to be equal. This is expressed in Equation (1).

$$
e_{t}=\frac{P_{t}}{P_{t}^{*}}
$$

where $e_{t}$ represents the exchange rate at time $t$; or the number of units of the domestic currency that are needed to buy one foreign currency. $P_{t}$ is the domestic price level at time $t$, and $P_{t}^{*}$ the level of foreign prices at time $t$.

Equation (1) implies that high or low levels of domestic prices relative to foreign prices will lead to high or low values of the local currency. Different levels of prices between the two countries will open the door for trade between them, pushing prices towards equality. This assumption may not always be valid, since markets are not always integrated. Therefore, it might affect the credibility of the hypothesis of the absolute PPP in the long run (Al-Zyoud, 2015).

The second form of PPP hypothesis is the relative form. It states that the percentage change in the exchange rate between two countries during any time period is equal to the difference between the percentage changes in price levels in the two countries (Lafrance \& Schembri, 2002). The relative form of PPP hypothesis can be expressed as follows:

$$
\frac{e_{t}-e_{t-1}}{e_{t-1}}=\frac{P_{t}-P_{t-1}}{P_{t-1}}-\frac{P_{t}^{*}-P_{t-1}^{*}}{P_{t-1}^{*}}
$$

Due to the lack of a conclusive opinion on the credibility of the PPP hypothesis in the long run, many studies addressed the hypothesis of PPP with its two forms, especially in periods of instability. Some of these studies have accepted the hypothesis of PPP, while others have rejected it. These different results make the question of the credibility of the hypothesis of PPP still open. These studies have differed in their testing methods and their goals.

In a study on African countries, Nagayasu (1998) tested whether the exchange rates in Africa are parallel and consistent with the hypothesis of the PPP in the long term. He used a panel-cointegration method, applied to sixteen African countries during the period 1981 to 1994. The results show that the behavior of the exchange rates in Africa is consistent with the PPP hypothesis in the long term.

Doğanlar (1999) tested the credibility of the hypothesis of the PPP on a group of Asian countries, including India, Indonesia, Pakistan, the Philippines, and Turkey. His study used the unit root test and cointegration technique. The results showed non stationarity of the nominal exchange rate and prices for these countries. In addition, the results showed no cointegration between the exchange rate and prices for most of these countries. These results led to the rejection of the hypothesis of PPP for these countries.

Nusair (2003) conducted a study on a group of Asian countries testing the PPP hypothesis during periods of floating exchange rates using the Augmented Dickey Fuller (ADF), Phillips Perron (PP), and Kwiatkowski Phillips Schmidt Shin (KPSS) unit root tests. His results confirmed what was found by Doğanlar (1999) for Asian countries.

To measure the effect of changing the method of judging the hypothesis of the PPP and changing the country that is selected as the trading partner, Abumustafa (2006) tested these changes in the case of Jordan. His study found that accepting or rejecting the hypothesis of PPP is affected by the method used to test the stationarity of the data. His study pointed to a lack of sensitivity of the results to changing the country that is selected as a trading partner.

Aslan \& Kula (2007) used more than one test to check the stationarity of data. They employed the ADF, PP, KPSS, and DF-GLS to examine the stationarity of the formal and informal Turkish exchange rates. All of results accepted the PPP hypothesis, contradicting the results of Abumustafa (2006).

Nazari \& Mobariak (2010)tested the hypothesis of PPP on a group of countries that are rich in natural resources, especially crude oil. They used annual panel data from 1974 to 2007. This study accepted the PPP hypothesis for oil exporting countries.

To test some of the structural changes for the Romanian economy during 1991to 2012, Ocal (2013) used the Zirot-Andrews test for stationarity. Ocal concluded to reject the hypothesis of PPP.

Jayaraman \& Choong (2014) tested the PPP hypothesis in the long term for a group of countries in the Pacific 
islands. Those countries are characterized by fixed exchange rate regimes. The study contradicts Ocal (2013), accepting the PPP hypothesis in the long term for all sample countries.

To test the credibility of the purchasing power parity hypothesis in its strong and weak forms, Al-Gasaymeh \& Kasem (2015) used monthly data from the Jordanian economy with its major trading partners, Japan, the United Kingdom, Turkey, and the United States for the period 2000-2012. The results showed nonstationarity of the real exchange rate data, or rejecting the hypothesis of PPP in the long term. The study also examined the weak form of the PPP hypothesis, using the cointegration technique. The results indicated the existence of cointegration between the exchange rate and the level of domestic and foreign prices for all these countries, meaning accepting the weak form of the PPP hypothesis.

Using monthly data for the period 1995 to 2008, Al-Zyoud (2015) tested the long-term movement of the exchange rate between the Canadian dollar and the US dollar with an Engle-Granger test for cointegration. The study did not prove the cointegration relationship between the actual exchange rate and the rate that represents purchasing power parity, meaning there is no relationship in the long-term. However, the study pointed out that the movements of relative prices are statistically significant in explaining the actual exchange between the American and Canadian rates.

Finally, the study of the ESCWA (2015) compared the behavior of PPP in 12 countries over the years (20112013). These countries are: Bahrain, Egypt Iraq Jordan Kuwait Oman, Palestine Qatar, Saudi Arabia, Sudan, United Arab Emirates, and Yemen. The main result of this study show that

The results show there is a variation of the purchasing power of the participating countries' national currencies over the years (2011-2013). Some countries witnessed growing trends in the purchasing power of their national currencies over 2012 and 2013 whereas some other experienced an inverted trend during the same period. Palestine is one of the countries which experienced a consecutive increase in the real purchasing power of its local currency at the GDP level. Conversely, a reversed trend is observed in Sudan where the purchasing power of the Sudanese Pound decreases dramatically in 2013 in comparison with 2012. It displays a drop of 60 per cent in 2013.

\section{The Methodology}

To test the credibility of the hypothesis of purchasing power parity for the Kuwaiti economy, this study uses some of the methods that were used in previous literature. The hypothetical exchange rate is calculated based on the work of Crownover, Pippenger, \& Steigerwald (1996), given by the following formula:

$$
\frac{S_{t}^{i j}}{S_{B}^{i j}}=\frac{\left(P_{t}^{i} / P_{B}^{i}\right)}{\left(P_{t}^{j} / P_{B}^{j}\right)}
$$

To calculate this hypothetical exchange rate, equation (3) can be re-written as in Equation (4).

$$
S_{t}^{i j}=S_{B}^{i j} \frac{\left(P_{t}^{i} / P_{B}^{i}\right)}{\left(P_{t}^{j} / P_{B}^{j}\right)}
$$

where $S_{t}^{i j}$ is the hypothetical exchange rate according to the theory of PPP for the period $t$. It represents the number of units of the currency of the country $i$ needed to buy one unit of the currency of country $j . S_{B}^{i j}$ is the actual exchange rate in the base year, $P_{t}^{i}$ is the domestic price in period $t, P_{B}^{i}$ is the domestic price in the base year, $P_{t}^{j}$ is the foreign price in period $t, P_{B}^{j}$ is the foreign price in the base year.

The econometric methods used in this paper include the unit root tests to examine the stationarity of the real exchange rate between the Kuwaiti dinar and the US dollar, as a proxy for the levels of foreign prices. We use both the Augmented Dickey Fuller (ADF) and Phillips Perron (PP) to test the unit root hypothesis, the nonstationarity of the variables. If the unit root hypothesis is rejected, then the PPP hypothesis is accepted. The hypothesis of PPP relies, as previously mentioned, on the law of one price. This law stipulates that after the elimination of transportation costs, taxes and tariffs on trade, the same good will be sold at the same price in different countries (Michael and Patricia, 2003). This can be expressed as shown in Equation (5).

$$
P_{i}=e P_{i}^{*}
$$


where $P_{i}$ represents the domestic price of the commodity $i, P_{i}^{*}$ is the foreign price of the commodity $i$, and $e$ is the exchange rate that represents the number of local units needed to buy one unit of foreign currency. When we deal with the law of one price to represent all goods and services in the economy instead of using the price of a signal commodity, then Equation (5) becomes:

$$
P=e P^{*}
$$

The PPP hypothesis predicts that the exchange rate will adapt to bring the equality of the level of prices between the two countries. This can be expressed in the following formula:

$$
e=\frac{P}{P^{*}}
$$

According to the PPP hypothesis, the ratio of the change in the price level between two countries will lead to a rise or fall in the nominal exchange rate by the same rate. This result can be examined by testing the stationarity of the real exchange rate. If the unit root hypothesis is rejected, then the hypothesis of PPP will be accepted. To test the stationarity of the real exchange rate, this research will mainly apply the Augmented Dickey Fuller (ADF) test, which depends on the regression estimation in Equation (8).

$$
\Delta Y_{t}=\beta_{1}+\beta_{2} T+\delta Y_{t-1}+\sum_{i=1}^{n} \alpha_{i} \Delta Y_{t-i}+\varepsilon_{t}
$$

where $Y_{t}$ represents the study variable (real exchange rate) in time $t, \varepsilon_{t}$ is the error term, and $T$ is time trend. The number of periods sufficient to cancel the autocorrelation in the error term, $n$, will be identified as the minimum value of the Schwartz Information Criteria (SIC).

If the calculated value, in absolute terms, is greater than the $\tau$ value of the critical extracted from the Mackinnon table, then the null hypothesis of no stationarity $\left(\mathrm{H}_{0}: \delta=0\right)$ will be rejected. We accept of the alternative hypothesis of stationary at the level (Gujarati \& Porter, 2009), and the PPP hypothesis will be accepted in its strong form.

\section{Empirical Results}

The stationarity of the real exchange rate is investigated using the ADF and PP tests. The null hypothesis of a unit root is tested with and without a time trend. The trend term is kept in the estimation only if it is significant at the 10 percent level; the results show that in both tests the trend was insignificant.

Table 1. Unit Root Tests for Kuwaiti Real Exchange Rate for the period (2006-2015)

\begin{tabular}{llc}
\hline & ADF test & PP test \\
\hline Ln (RX) & $-2.292^{*}(1)$ & $-2.155^{*}(4)$ \\
\hline
\end{tabular}

Notes. (PP) stands for the Phillips-Perron and (ADF) stands for Augmented Dickey Fuller.

The numbers inside parentheses for the ADF test are the numbers of lags in the ADF test chosen by minimizing Schwartz Information Criteria (SIC).

* indicates significant at 10 percent level or better.

All variables are transformed by taking their natural logarithm.

The results, shown in Table 1, indicate that the real exchange rate is non-stationary in its level whether applying the ADF or the PP unit root test of the real exchange rate. These findings show very little support for PPP in the case of Kuwait. However, these results are consistent with previous studies such as Al-Zyoud (2015) and Ocal (2013).

\subsection{How to Interpret This Result?}

The PPP hypothesis may not to be applicable to the case of Kuwait because of the behavior of the components of the real exchange rate itself. The real exchange rate consists of the nominal exchange rate in addition to the local CPI and foreign CPI, which is represented by the CPI of the United States. The nominal exchange rate itself 
shows non-stationarity in its series, whether a trend is included or not.(the results of this test are available upon request). In fact, the nominal exchange rate for Kuwait was increasing during the period $2006-2015$ by $4 \%$.

Regarding the levels of price in both countries, we have the following comments.

As indicated by Table 2, the correlation between the growth rates of the two CPI series for the whole period is weak, indicating that the two series are not moving together to show stability or stationarity in the real exchange rate series. The correlation between the growth rates was the highest in 2007 with a coefficient value of 0.86 . However, more than half of the sample data shows a negative correlation, indicating a movement in the opposite directions between the two countries.

Table 2. The correlation between CPI growth rates in Kuwait and the US

\begin{tabular}{ll}
\hline Year & Correlation \\
\hline 2007 & 0.86 \\
2008 & 0.69 \\
2009 & -0.30 \\
2010 & -0.77 \\
2011 & -0.31 \\
2012 & 0.60 \\
2013 & -0.24 \\
2014 & -0.51 \\
2015 & 0.15 \\
\hline
\end{tabular}

When examining the details of the CPI components, we found that two main sectors constitute about $50 \%$ of the CPI basket. These two sectors are "housing" and "food and beverages". We believe that these two sectors should represent the behavior of the other sectors in the basket that constitute the CPI. When studying the growth rates of these two sectors, it was found that the correlation between these two sectors in Kuwait and the US is weak as shown in Figures 1 and 2. The two graphs combine the movements of the growth rates of the "housing" and "food and beverages" sectors in Kuwait and the US to show whether the correlation is strong or weak between the two series. The graphs indicate that the correlation between the two main components of the CPI is low and does not support the PPP hypothesis. In other words, if the prices indices of the two sectors move together, they would show a stable ratio, or stationarity, and will help to support the PPP hypothesis.

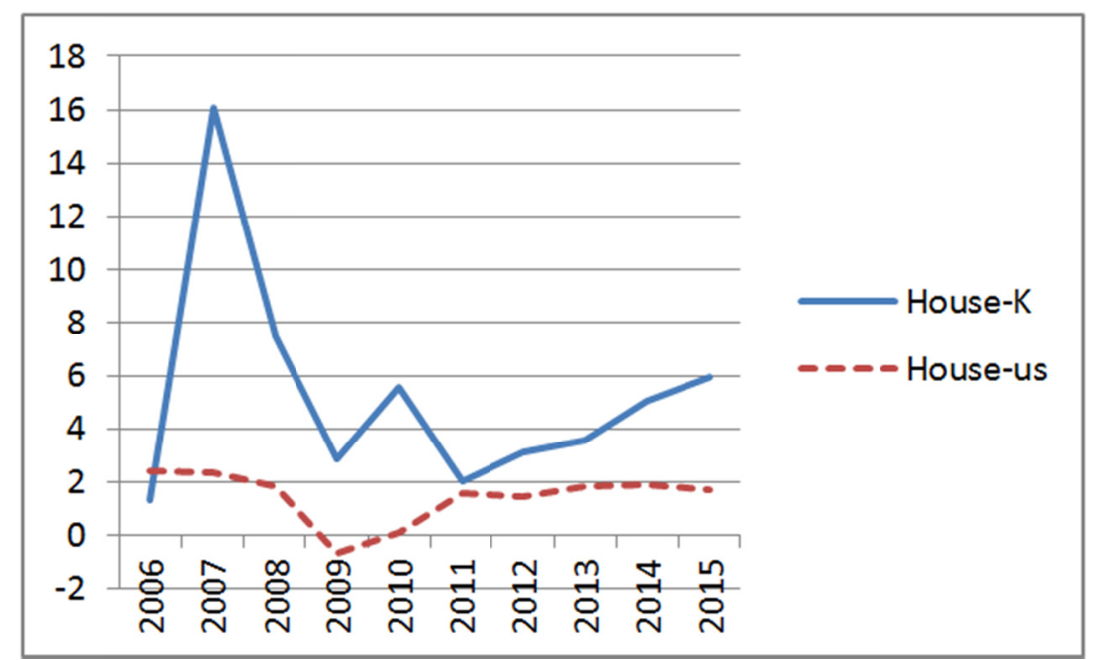

Figure 1. The growth rates of the "housing" sector in Kuwait and the US for the period (2006-2015)

Note. Source: Kuwait Central Statistical Bureau and St. Louis Federal Reserve. 


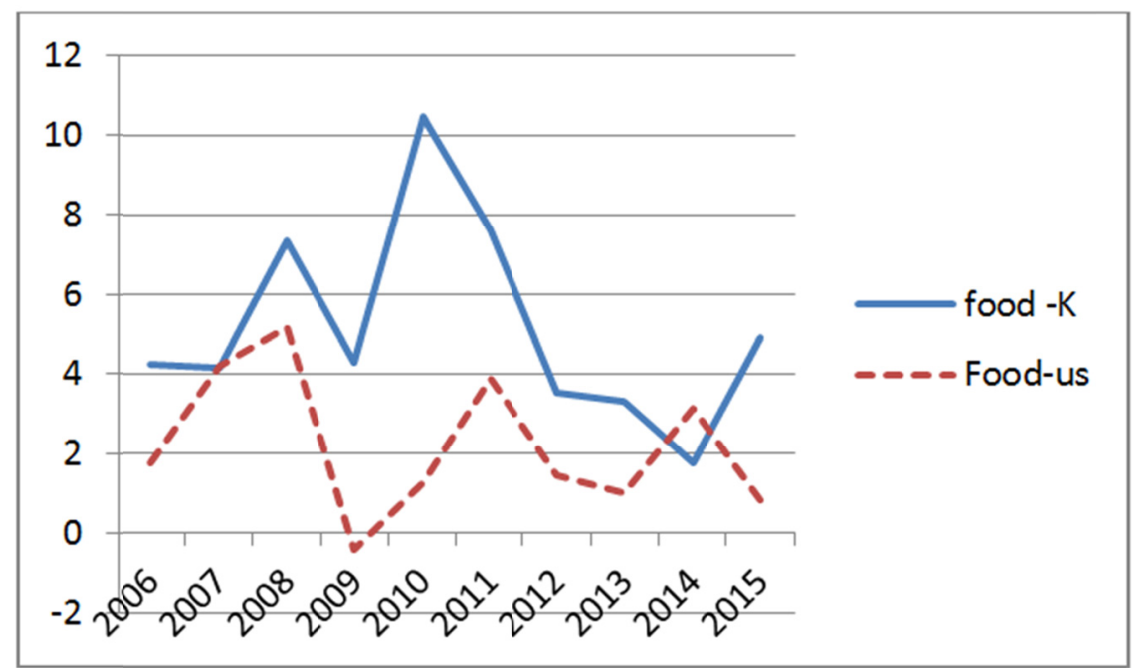

Figure 2. The growth rates of the "food and beverages" sector in Kuwait and the US for the period (2006-2015)

Note. Source: Kuwait Central Statistical Bureau and St. Louis Federal Reserve.

The average growth rates for "housing" and "food and beverages" sectors were $5.1 \%$ and $5.3 \%$, respectively, in Kuwait. They were $2.2 \%$ and $1.5 \%$, respectively, in the US for the period $2006-2015$ (Central Statistical Bureau of Kuwait; St. Louis Federal Reserve). These numbers show the big gaps between the levels of prices between the two countries. In fact, they support the idea that the PPP hypothesis for Kuwait is not valid.

\section{Conclusion}

This study tests the validity of the purchasing power parity theory in Kuwait from 2006 to 2015 using two unit root tests. The results did not confirm the stationarity of the real exchange rate of Kuwait. When the real exchange rate is a non-stationary series, this does not support the 'Law of One Price'. However, such a result was not surprising. This result is consistent with other studies like Al-Gasaymeh \& Kasem (2015) and Ocal (2013).

When testing "the law of one price" between Kuwait and the United States, the data show weak correlations between the price levels in the two countries. Thus, the law of one price is rejected. One main reason for that result is the big gap between the levels of prices between the two countries. Kuwait shows much higher rates of growth of prices in many sectors when compared to the US. These results give important implications for Kuwait that the PPP formula is not going in favor for its economy. With this trend in the real exchange rare, the average Kuwaiti will need more Kuwaiti dinar to import the same amount of foreign products over time.

\section{Reference}

Abumustafa, N. (2006). New Evidence of the Validity of Purchasing Power Parity from Jordan. Applied Economics Letters, 13(6), 379-383. http://dx.doi.org/10.1080/13504850600639084

Al-Gasaymeh, A., \& Kasem, J. (2015). Purchasing Power Parity and Country Characteristics: Evidence from Panel Data Tests. Global Economy and Finance Journal, 8(2), 63-77. http://dx.doi.org/10.21102/gefj.2015.09.82.05

Al-Zyoud, H. (2015). An Empirical Test of Purchasing Power Parity Theory for Canadian Dollar-US Dollar Exchange Rates. International Journal of Economics and Finance, 7(3), 233-240. http://dx.doi.org/10.5539/ijef.v7n3p233

Aslan, A., \& Kula, F. (2007). Examining the Validity of PPP: The Black Market Exchange Rate Versus Official Rate. Journal of Economics and Business, X (2), 83-92.

Crownover, C., Pippenger, J., \& Steigerwald, D. (1996). Testing for Absolute Purchasing Power Parity. Journal of International Money and Finance, 15(5), 783-796.

Doğanlar, M. (1999). Testing Long-Run Validity of Purchasing Power Parity for Asian Countries. Applied Economic Letters, 6(3), 147-51.

ESCWA. (2015). Purchasing Power Parities and the Real Size of Western Asia Economies A Comprehensive 
Report of the 2011 Round of the International Comparison Program in Western Asia Region. Technical Paper, 2. New York, United Nations.

Gujarati, D., \& Porter, D. (2009). Basic Econometrics (5th Ed.). New York, NY: Mc Grow-hill Irwin.

Holmes, M. (2001). New Evidence on Real Exchange Rate Stationarity and Purchasing Power Parity in Less Developed Countries. Journal of Macroeconomics, 23(4), 601-614.

Jayaraman, T., \& Choong, C. (2014). Purchasing Power Parity Theory and its Validity in Pacific Island Countries. Bank of Valletta Review, 48, 41-52.

Lafrance, R., \& Schembri, L. (2002). Purchasing-Power Parity: Definition, Measurement and Interpretation. Bank of Canada Review, Autumn, 27-33

Nagayasu, J. (1998). Does the Long-Run PPP Hypothesis Hold for Africa?: Evidence from Panel Co-Integration Study. IMF working paper, 98/123.

Nusair, S. (2003). Testing the Validity of Purchasing Power Parity for Asian countries during the Current Float. Journal of Economic Development, 28(2), 129-147.

Ocal, O. (2013). Purchasing Power Parity in the Case of Romania: Evidence from Structural Breaks. International Journal of Economics and Financial Issues, 3(4), 973-976.

Shapiro, A. (2006). Multinational Financial Management (8th Ed.), Hoboken, New Jersey: Wiley, Inc.

\section{Copyrights}

Copyright for this article is retained by the author(s), with first publication rights granted to the journal.

This is an open-access article distributed under the terms and conditions of the Creative Commons Attribution license (http://creativecommons.org/licenses/by/4.0/). 